Article

\title{
Further Mulinane and Azorellane Diterpenoids Isolated from Mulinum crassifolium and Azorella compacta
}

Jorge Bórquez ${ }^{1}$, Alejandro Ardiles ${ }^{1,6}$, Luis Alberto Loyola ${ }^{1}$, Luis Manuel Peña-Rodriguez ${ }^{2}$, Gloria María Molina-Salinas ${ }^{3,4}$, Javier Vallejos ${ }^{5}$, Isidro G. Collado ${ }^{6}$ and Mario J. Simirgiotis ${ }^{1, *}$

1 Laboratorio de Productos Naturales, Departamento de Química, Universidad de Antofagasta, Av. Coloso S-N, Antofagasta 1240000, Chile; E-Mails: jorge.borquez@uantof.cl (J.B.); euro_ale@hotmail.com (A.A.); alberto.loyola@uantof.cl (L.A.L.)

2 Grupo de Química Orgánica, Unidad de Biotecnología, Centro de Investigación Científica de Yucatán, Calle 43 No 130, Colonia Chuburná, Mérida, Yucatán 97200, Mexico;

E-Mail: luispenarodriguez@yahoo.com

3 División de Biología Celular y Molecular, Centro de Investigación Biomédica del Noreste, Instituto Mexicano del Seguro Social, San Luis Potosí y Dos de Abril, Colonia Independencia, Monterrey, Nuevo León 64720, Mexico; E-Mail: gmolina70@gmail.com

4 Unidad de Alta Especialidad Médica Yucatán Lic. Ignacio García Téllez Calle 41 No 439 x 32 y 34, Col. Industrial, CP 97150, Mérida, Yucatan 97200, Mexico

5 Departamento de Química, Universidad Católica del Norte, Av. Angamos 610, Antofagasta 1240000, Chile; E-Mail: jvallejos01@ucn.cl

6 Departamento de Química Orgánica, Facultad de Ciencias, Universidad de Cádiz, Apartado Postal 40, Puerto Real 11510, Spain; E-Mail: isidro.gonzalez@uca.es

* Author to whom correspondence should be addressed; E-Mail: mario.simirgiotis@uantof.cl; Tel.: +56-55-637-229; Fax: +56-55-637-457.

Received: 3 March 2014; in revised form: 19 March 2014 / Accepted: 21 March 2014 / Published: 28 March 2014

\begin{abstract}
The new mulinane diterpenoids $\mathbf{1}$ and $\mathbf{2}$ were isolated from the EtOAc extract of Mulinum crassifolium, while the rearranged mulinane 5, which was isolated for the first time from a natural source, was isolated from Azorella compacta. Compounds 1-2 were prepared by semi-synthesis thorough acetylation of the diterpene 17-acetoxymulinic acid (3). A mechanism of reaction was proposed, while the structures of the new compounds were elucidated on the basis of comprehensive spectroscopic analysis and computational methods.
\end{abstract}


Keywords: mulinanes; azorellanes; new diterpenoids; Chilean native plants; semisynthesis

\section{Introduction}

Mulinum crassifolium is a $15 \mathrm{~cm}$ small cushion shrub, which grows in the north of Chile at altitudes above 4,000 $\mathrm{m}$. This plant (Figure 1 left), commonly known as "chuquican" or "espinilla" is used in folk medicine, principally against diabetes and bronchial and intestinal disorders [1]. Mulinum crassifolium is well recognized as an important source of diterpenes bearing the mulinane skeleton, while Azorella compacta, another cushion shrub known as "llareta" (Figure 1 right) is a source of diterpenoids with both the mulinane and azorellane skeletons [2-4]. There is a phylogenetic relationship between these two shrubs, both belonging to the group Azorella (Apiaceae). This group includes six genera (Azorella, Laretia, Schizeilema, Mulinum, Huanaca, and Stilbocarpa) with Austral-Antarctic affinities and a geographic distribution that extends from Oceania to South America. The "Mulinum clade" is further divided into six subclades, which collectively include 23 of 26 species of Azorella, the monotypic Laretia and all species of Mulinum [5]. The rare diterpenoids isolated from these genera have displayed a wide variety of interesting biological activities, including trypanosomicidal [6], trichomonicidal [7], toxoplasmocidal [8], antiplasmodial [9], antibacterial [10], spermicidal [11], antihyperglycemic [12], antitubercular [13], antiinflamatory and analgesic activities $[14,15]$. In our continuing efforts in the search for the structurally diverse and biologically important metabolites from the genus Azorella [4,7,16] and Mulinum [4], two new mulinane diterpenoids, named mulinones a-b (compounds 1 and 2, Figure 2) were isolated from M. crassifolium together with 17-acetoxymulinic acid (3) and mulinolic acid (4). The rearranged mulinane $\mathbf{5}$, which is a new natural product but was previously reported as a reaction product [15], together with the known compounds azorellanol (6), and 13,14-dihydroxymulin-11-en-20-oic acid (7), were isolated from A. compacta. Compounds $\mathbf{1}, \mathbf{2}$ and $\mathbf{5}[14,15]$ were synthesized from their precursor natural products.

Figure 1. Pictures of Mulinum crassifolium (left) and Azorella compacta (right), from Northern Chile. (Taken by Jorge Bórquez and Mario J. Simirgiotis, on March 2011).
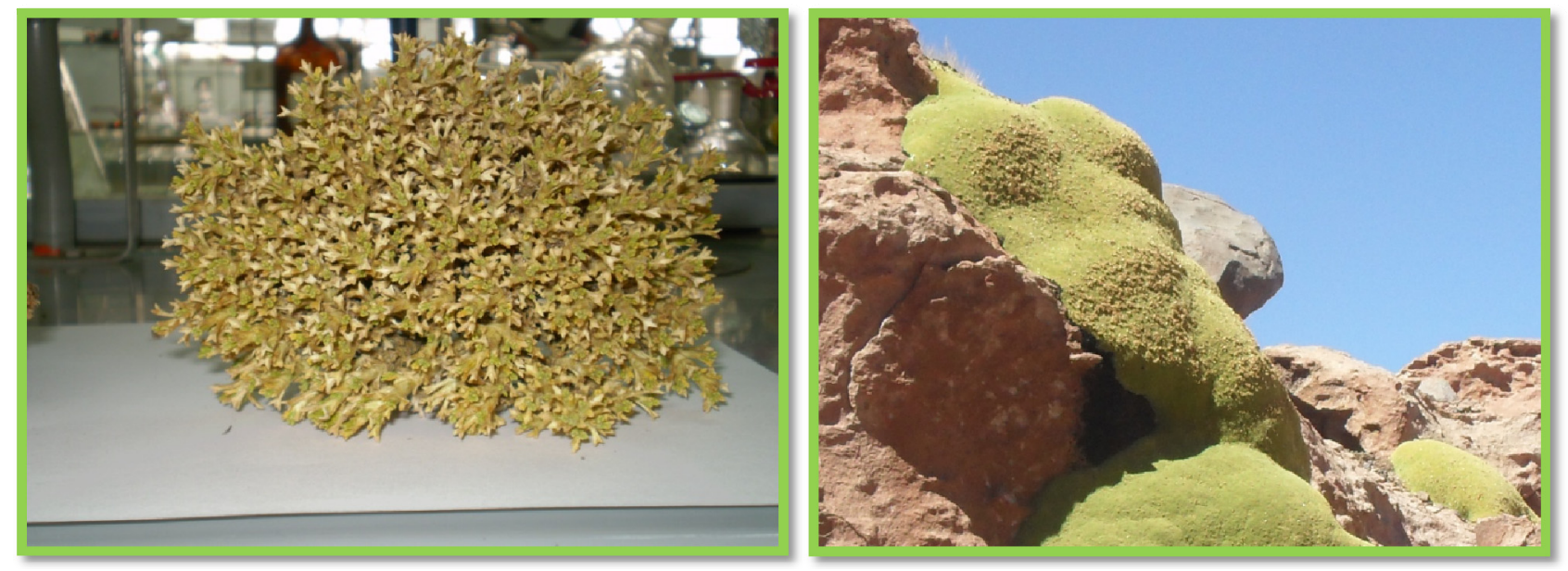
Figure 2. Structures of the diterpenoids isolated from Mulinum crassifolium and Azorella compacta.
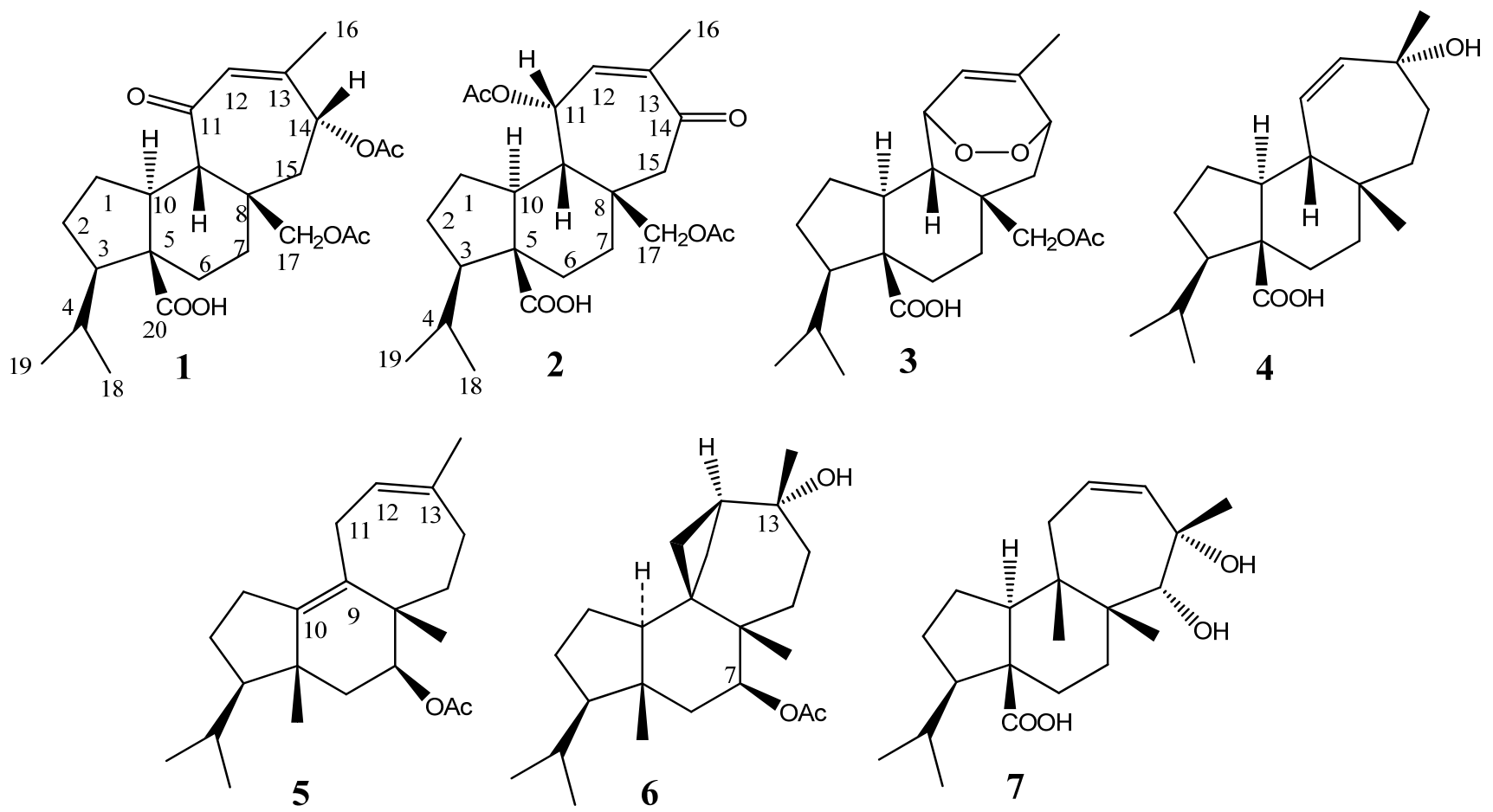

This paper deals with the isolation and structural elucidation of the new compounds. Furthermore the semi-synthesis of compounds 1, 2 from the parent compound 3 (Figure 2) and the proposed mechanism of reaction were addressed.

\section{Results and Discussion}

\subsection{Isolation and Structural Elucidation of the New Diterpenoids}

From the ethyl acetate extracts of the aerial parts of the Chilean cushion shrubs Mulinum crassifolium and Azorella compacta two new diterpenoids (compounds 1 and 2, Figure 2) were isolated together with five known compounds (compounds 3-7, Figure 2, for details please see the experimental part). These new compounds along with the new natural product 5 were semi-synthesized; compounds 1-2 from 17-acetoxymulinic acid 3, while compound 5, which is isolated for the first time from a plant, was previously synthesized from the azorellane diterpenoid 6 [15]. This fact confirmed their precursor natural products. The compounds isolated were proved not to be artifacts of the extraction procedure with ethyl acetate by extracting a portion of the plant material in the presence of calcium carbonate $(0.1 \%)$. The same natural products were detected and isolated using this procedure. The structural elucidation of the new compounds and proposed mechanism of reaction is explained below.

HREIMS of 1 showed an ion consistent with a molecular formula of $\mathrm{C}_{24} \mathrm{H}_{34} \mathrm{O}_{7}$ (required: $\mathrm{m} / z$ 434.2304, found 434.2284). The total of 24 carbons suggested the presence of a diacetylated diterpene. The ${ }^{1} \mathrm{H}-\mathrm{NMR}$ and ${ }^{13} \mathrm{C}-\mathrm{NMR}$ spectral data were easily assigned by comparison with NMR data of related compounds and in particular with the parent compound 17-acetoxymulinic acid $[9,17,18]$ (Tables 1 and 2, Figures S1-S8, Supplementary Material). The chemical shift values of the cyclopentane 
and cyclohexane rings were practically identical, confirming the configuration of the stereogenic centers and substitution pattern. The remaining signals indicated the presence of a trisubstituted double bond in the seven membered ring $\left(\delta_{\mathrm{C}-12} 127.1, \mathrm{~d}\right.$, and $\left.\delta_{\mathrm{C}-13} 150.5, \mathrm{~s}\right)$, together with the corresponding signal of one vinylic proton $\left(\delta_{\mathrm{H}-12} 5.84 \mathrm{brs}\right)$, a secondary acetoxyl group $\left(\delta_{\mathrm{H}-14} 5.75, \mathrm{dd}, J=11.3,3.8\right.$; $\left.\delta_{\mathrm{C}-14} 71.5, \mathrm{~d}\right)$ and a ketone $\left(\delta_{\mathrm{C}-11} 202.6, \mathrm{~s}\right)$. HMBC cross-peaks of the proton at $\delta_{\mathrm{H}} 2.63(\mathrm{H}-9)$ with C-11 (202.6) and $\mathrm{C}-12$ (127.1) suggested the presence of an $\alpha, \beta$-unsaturated ketone. The methyl group $\mathrm{CH}_{3}-16$ showed HMBC correlations to three carbons $(\mathrm{C}-12, \mathrm{C}-13$ and $\mathrm{C}-14)$ which confirmed the position of the double bond. The methyl group at $\delta_{\mathrm{H}} 2.11(3 \mathrm{H}, \mathrm{s}, \mathrm{H}-22)$ showed cross-peaks with C-21 and $\mathrm{C}-14$, while $\mathrm{H}-14\left(\delta_{\mathrm{H}}\right.$ 5.75) showed cross peaks with $\mathrm{C}-12, \mathrm{C}-13$ and $\mathrm{C}-15$, which further confirmed the position of the additional acetyl group on $\mathrm{C}-14$. The main results from phase sensitive NOESY spectra (Table 1, Figure S7) suggested that $\mathbf{1}$ had the stereochemistry shown in Figure 2. Proton $\mathrm{H}-14$ showed dipolar correlations with $\mathrm{H}-17$ and $\mathrm{H}-9$ protons, both with $\beta$ configuration; this fact confirmed the $\alpha$-orientation of the acetyl group on C-14. All the spectroscopic evidence stated above proved that $\mathbf{1}$ has the relative stereochemistry as proposed.

Table 1. ${ }^{1} \mathrm{H}-\mathrm{NMR}$ data, $\mathrm{HMBC}$ and NOE correlations for compounds $\mathbf{1}$ and $\mathbf{2}$ in $\mathrm{CDCl}_{3}$ ( $J$ in $\mathrm{Hz}$ in parentheses).

\begin{tabular}{|c|c|c|c|c|c|c|}
\hline \multirow[b]{2}{*}{ Proton } & \multicolumn{3}{|c|}{1} & \multicolumn{3}{|c|}{2} \\
\hline & $\begin{array}{l}\delta_{\mathrm{H}} \text { mult. } \\
(J \text { in } \mathrm{Hz})\end{array}$ & $\begin{array}{l}\text { HMBC } \\
(\mathbf{H} \rightarrow \mathbf{C})\end{array}$ & NOE & $\begin{array}{l}\delta_{\mathrm{H}} \text { mult. } \\
(\boldsymbol{J} \text { in } \mathrm{Hz})\end{array}$ & $\begin{array}{l}\text { HMBC } \\
(H \rightarrow C)\end{array}$ & NOE \\
\hline $1 \alpha$ & $1.24 \mathrm{~m}$ & C-5, 9 & & $1.83 \mathrm{~m}$ & - & - \\
\hline $1 \beta$ & $\begin{array}{c}1.84 \mathrm{dd} \\
(11.4,4.7)\end{array}$ & - & & $1.37 \mathrm{~m}$ & - & - \\
\hline $2 \alpha$ & $1.97 \mathrm{~m}$ & - & & $1.79 \mathrm{~m}$ & - & - \\
\hline $2 \beta$ & $1.58 \mathrm{~m}$ & - & & $1.48 \mathrm{~m}$ & - & - \\
\hline $3 \alpha$ & $1.48 \mathrm{~m}$ & - & & $1.35 \mathrm{~m}$ & $\begin{array}{c}\mathrm{C}-2,4,5,18 \\
19\end{array}$ & $\mathrm{H}-10 \alpha$ \\
\hline 4 & $1.54 \mathrm{~m}$ & - & & $1.45 \mathrm{~m}$ & - & - \\
\hline $6 \alpha$ & $1.43 \mathrm{~m}$ & - & & $1.22 \mathrm{~m}$ & - & $H-10 \alpha$ \\
\hline $6 \beta$ & $1.52 \mathrm{~m}$ & - & & $\begin{array}{c}2.45 \mathrm{dt} \\
(7.2,4.0)\end{array}$ & $\mathrm{C}-5,8$ & $\begin{array}{l}\text { Н-7 } \beta, \\
\text { Мe-19 }\end{array}$ \\
\hline $7 \alpha$ & $\begin{array}{c}2.56 \mathrm{dt} \\
(13.3,3.2)\end{array}$ & $\begin{array}{c}\mathrm{C}-15,9 \\
17\end{array}$ & & $\begin{array}{c}1.80 \mathrm{dd} \\
(13.6,4.5)\end{array}$ & - & - \\
\hline $7 \beta$ & $1.59 \mathrm{~m}$ & - & & $\begin{array}{c}1.71 \mathrm{dt} \\
(14.3,4.3)\end{array}$ & C-8, 9, 15 & 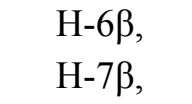 \\
\hline $9 \beta$ & $2.63 \mathrm{~m}$ & $\begin{array}{c}\mathrm{C}-7,15, \\
10,11\end{array}$ & & $2.23 \mathrm{~m}$ & $\begin{array}{c}\mathrm{C}-8,10,11 \\
12,15\end{array}$ & $\begin{array}{l}\mathrm{H}-11 \beta \\
\mathrm{H}-17 \beta\end{array}$ \\
\hline $10 \alpha$ & $2.22 \mathrm{~m}$ & $\begin{array}{c}\mathrm{C}-20,9 \\
5,8,6\end{array}$ & $\begin{array}{c}\mathrm{H}-1 \alpha, \mathrm{H}-6 \alpha \\
\mathrm{H}-3 \alpha\end{array}$ & $1.51 \mathrm{~m}$ & C- $1,5,9$ & H- $6 \alpha, H-3 \alpha$ \\
\hline $11 \beta$ & - & - & & $\begin{array}{c}5.94 \mathrm{br} \mathrm{d} \\
(2.4)\end{array}$ & $\begin{array}{c}\mathrm{C}-8,9,10 \\
12,21\end{array}$ & $\begin{array}{l}\mathrm{H}-9 \beta \\
\mathrm{H}-17 \beta\end{array}$ \\
\hline 12 & 5.84 br s & $\begin{array}{c}\text { C-9, 13, } \\
14\end{array}$ & & $6.20 \mathrm{br} \mathrm{s}$ & $\begin{array}{c}\mathrm{C}-9,13,14 \\
16\end{array}$ & H-11, H-16 \\
\hline 14 & $\begin{array}{c}5.75 \mathrm{dd} \\
(11.3,3.8)\end{array}$ & $\begin{array}{c}\mathrm{C}-12,13, \\
15\end{array}$ & $\begin{array}{l}\mathrm{H}-17 \beta, \mathrm{H}- \\
15 \beta, \mathrm{H}-9 \beta\end{array}$ & - & - & - \\
\hline
\end{tabular}


Table 1. Cont.

\begin{tabular}{|c|c|c|c|c|c|c|}
\hline \multirow[b]{2}{*}{ Proton } & \multicolumn{3}{|c|}{1} & \multicolumn{3}{|c|}{2} \\
\hline & $\begin{array}{l}\delta_{\mathrm{H}} \text { mult. } \\
(\boldsymbol{J} \text { in } \mathrm{Hz})\end{array}$ & $\begin{array}{l}\mathrm{HMBC} \\
(\mathrm{H} \rightarrow \mathrm{C})\end{array}$ & NOE & $\begin{array}{l}\delta_{H} \text { mult. } \\
(J \text { in } \mathrm{Hz})\end{array}$ & $\begin{array}{l}\text { HMBC } \\
(\mathrm{H} \rightarrow \mathrm{C})\end{array}$ & NOE \\
\hline $15 \alpha$ & $\begin{array}{c}261 \mathrm{dd} \\
(14.1,11.3)\end{array}$ & $\begin{array}{c}\mathrm{C}-14,7 \\
17,13\end{array}$ & & $2.62 \mathrm{~d}(12.7)$ & $\begin{array}{c}\mathrm{C}-14,7,17 \\
13,8\end{array}$ & - \\
\hline $15 \beta$ & $\begin{array}{c}1.68 \mathrm{dd} \\
(14.1,3.8)\end{array}$ & - & & $2.50 \mathrm{~d}(12.7)$ & - & - \\
\hline 16 & $1.85 \mathrm{br} \mathrm{s}$ & $\begin{array}{c}\mathrm{C}-13,12, \\
14\end{array}$ & & $1.87 \mathrm{br} \mathrm{s}$ & $\mathrm{C}-13,12,14$ & - \\
\hline $17 \alpha$ & $3.85 \mathrm{~d}(11.3)$ & C-9, 7, 15 & & $3.94 \mathrm{~d}(11.1)$ & C-8, 9, 15 & - \\
\hline $17 \beta$ & $4.17 \mathrm{~d}(11.3)$ & - & $\begin{array}{c}\mathrm{H}-14 \beta, \\
\mathrm{H}-15 \beta\end{array}$ & $4.00 \mathrm{~d}(11.1)$ & - & $\begin{array}{l}\mathrm{H}-9 \beta \\
\mathrm{H}-11 \beta\end{array}$ \\
\hline 18 & $0.85 \mathrm{~d}(5.5)$ & C- $-4,3$ & & $1.99 \mathrm{~d}(6.3)$ & $\mathrm{C}-4,3$ & - \\
\hline 19 & $1.02 \mathrm{~d}(5.5)$ & $\mathrm{C}-4,3$ & & $0.82 \mathrm{~d}(6.3)$ & $\mathrm{C}-4,3$ & - \\
\hline 22 & $2.11 \mathrm{~s}$ & $\mathrm{C}-21,14$ & & $2.09 \mathrm{~s}$ & - & - \\
\hline 24 & $1.99 \mathrm{~s}$ & $\mathrm{C}-23,17$ & & $2.04 \mathrm{~s}$ & C-23, 17 & - \\
\hline
\end{tabular}

Table 2. ${ }^{13} \mathrm{C}-\mathrm{NMR}$ data (100.25 MHz) for the new compounds $\mathbf{1}$ and $\mathbf{2}$.

\begin{tabular}{lccccl}
\hline C\# & \multicolumn{1}{c}{$\mathbf{1}$} & $\mathbf{2}$ & $\mathbf{C \#}$ & \multicolumn{1}{c}{$\mathbf{1}$} & \multicolumn{1}{c}{$\mathbf{2}$} \\
\hline 1 & $24.2 \mathrm{t}$ & $25.7 \mathrm{t}$ & 13 & $150.5 \mathrm{~s}$ & $138.1 \mathrm{~s}$ \\
2 & $28.4 \mathrm{t}$ & $28.5 \mathrm{t}$ & 14 & $71.5 \mathrm{~d}$ & $201.7 \mathrm{~s}$ \\
3 & $57.5 \mathrm{~d}$ & $57.3 \mathrm{~d}$ & 15 & $36.2 \mathrm{t}$ & $52.5 \mathrm{t}$ \\
4 & $31.6 \mathrm{~d}$ & $31.6 \mathrm{~d}$ & 16 & $28.4 \mathrm{q}$ & $18.5 \mathrm{q}$ \\
5 & $57.0 \mathrm{~s}$ & $56.1 \mathrm{~s}$ & 17 & $71.6 \mathrm{t}$ & $71.0 \mathrm{t}$ \\
6 & $31.6 \mathrm{t}$ & $32.7 \mathrm{t}$ & 18 & $22.7 \mathrm{q}$ & $22.6 \mathrm{q}$ \\
7 & $36.0 \mathrm{t}$ & $34.3 \mathrm{t}$ & 19 & $22.3 \mathrm{q}$ & $22.3 \mathrm{q}$ \\
8 & $46.8 \mathrm{~s}$ & $37.9 \mathrm{~s}$ & 20 & $178.4 \mathrm{~s}$ & $178.1 \mathrm{~s}$ \\
9 & $57.4 \mathrm{~d}$ & $45.9 \mathrm{~d}$ & 21 & $170.5 \mathrm{~s}$ & $170.7 \mathrm{~s}$ \\
10 & $46.9 \mathrm{~d}$ & $47.3 \mathrm{~d}$ & 22 & $20.9 \mathrm{q}$ & $21.2 \mathrm{q}$ \\
11 & $202.6 \mathrm{~s}$ & $72.2 \mathrm{~d}$ & 23 & $169.5 \mathrm{~s}$ & $169.9 \mathrm{~s}$ \\
12 & $127.1 \mathrm{~d}$ & $139.2 \mathrm{~d}$ & 24 & $20.5 \mathrm{q}$ & $20.8 \mathrm{q}$ \\
\hline
\end{tabular}

The diterpenoid 2 had the same molecular formula $\left(\mathrm{C}_{24} \mathrm{H}_{34} \mathrm{O}_{7}\right.$, (required: $\mathrm{m} / \mathrm{z} 434.2304$, found 434.2348), as 1, and showed a similar IR spectrum. The ${ }^{13} \mathrm{C}$-NMR spectrum exhibited 24 peaks (Table 2) while the DEPT-135 showed evidence for the same numbers of methyl, methylene, methine and quaternary (including four carbonyls) carbons, as compound 1. However, in the ${ }^{1} \mathrm{H}-\mathrm{NMR}$ spectra the simplification in the coupling pattern of the methylene protons $\left(\delta_{\mathrm{H} 15 \alpha} 2.62, \mathrm{~d}, J=12.7\right.$ and $\delta_{\mathrm{H} 15 \beta} 2.50$, $\mathrm{d}, J=12.7)$ of the cycloheptane ring as well as the strong deshielding of the beta oriented one which appeared as a broad doublet $\left(\delta_{\mathrm{H} 11} 5.94\right.$, brd, $\left.J=2.4\right)$ suggested that the location of the keto carbonyl group was at C-14. Moreover, in the ${ }^{13} \mathrm{C}-\mathrm{NMR}$ spectrum of compound 2, C-14 showed a big upfield shift $\left.\delta \mathrm{C}_{14}=201.7\right)$, whereas $\mathrm{C}-11$ showed a downfield shift $\left(\delta \mathrm{C}_{11}=72.2\right)$, this suggested that the keto group is placed at C-14 while the acyl group is at C-11 (See Figures S9-S16). The structure of 2 was confirmed by careful analysis of the HMBC spectra (Table 1, Figure S16). Strong correlations were observed between the signal at $\delta_{\mathrm{H}} 1.87(3 \mathrm{H}, \mathrm{s})$ assigned to $\mathrm{CH}_{3}-16$, and signals at $\delta_{\mathrm{C}} 139.2(\mathrm{~d}$, olefin 
$\mathrm{C}-12$ ), $\delta_{\mathrm{C}} 138.1$ (s, olefin C-13) and $\delta_{\mathrm{C}} 201.7$ (s, carbonyl C-14). The signals at $\delta_{\mathrm{H}} 2.62$ and 2.50 assigned to $\mathrm{H}-15 \alpha$ and $\mathrm{H}-15 \beta$ correlated with the signal at $\delta_{\mathrm{C}} 201.7$ (s, carbonyl C-14), $\delta_{\mathrm{C}} 138.1$ (s, olefinic $\mathrm{C}-13$ ) and 71.0 ( $\mathrm{t}, \mathrm{CH}_{2} \mathrm{OAc}, \mathrm{C}-17$ ). These facts confirmed the location of the keto group at $\mathrm{C}-14$ and the assignment of a double bond between $\mathrm{C}-12$ and $\mathrm{C}-13$. The location of the acetyl groups at C-17 and C-11 was confirmed by the correlation of the protons $\mathrm{CH}_{2} \mathrm{OAc}\left(\mathrm{C}-17, \delta_{\mathrm{H}} 3.94\right.$ and 4.00 , both, $\mathrm{d}, \mathrm{J}=11.1 \mathrm{~Hz})$ with $\mathrm{C}-8, \mathrm{C}-9$ and $\mathrm{C}-15$ and the proton CHOAc $\left(\mathrm{C}-11, \delta_{\mathrm{H}} 5.94\right.$, brd, $\left.\mathrm{J}=2.4 \mathrm{~Hz}\right)$ with C-8, C-9, C-10 and C-12. Hence, the relative stereochemistry of 2 corresponds to mulin-12-en-11 $\alpha, 17-$ diacetoxy-14-one-20-oic acid (Figure 2).

\subsection{Semisynthetic Procedures and Proposed Mechanisms of Reaction}

Compounds 1, 2 and 5 were prepared from their precursors 3 and $\mathbf{6}$. The reactions are explained below.

\subsubsection{Semi-Synthesis of Compounds $\mathbf{1}$ and $\mathbf{2}$}

Treatment of $\mathbf{3}$, with pyridine- $\mathrm{Ac}_{2} \mathrm{O}$, at $25^{\circ} \mathrm{C}$ under inert atmosphere yielded compounds $\mathbf{1}$ and $\mathbf{2}$. The proposed mechanism of the reaction is shown in Figure 3. The two reaction pathways $\mathbf{a}-\mathbf{b}$ shown for compound 3 can be explained by a mechanism in which the base pyridine abstracts a proton from either the a or b sides $\left(\mathrm{H}_{11}\right.$ or $\mathrm{H}_{14}$, respectively, Figure 3$)$ of the mulinane skeleton leading to the opening of the endoperoxide ring with simultaneous formation of an $\alpha$ - $\beta$-unsaturated carbonyl followed, by acylation of the remaining oxygen anion with $\mathrm{Ac}_{2} \mathrm{O}$ leading to the mulinane compounds 1 and $2(79.2 \%$ and $13 \%$ yield, respectively).

Figure 3. Proposed rearrangement of 3 with $\mathrm{Ac}_{2} \mathrm{O}$ in pyridine at $25^{\circ} \mathrm{C}$.

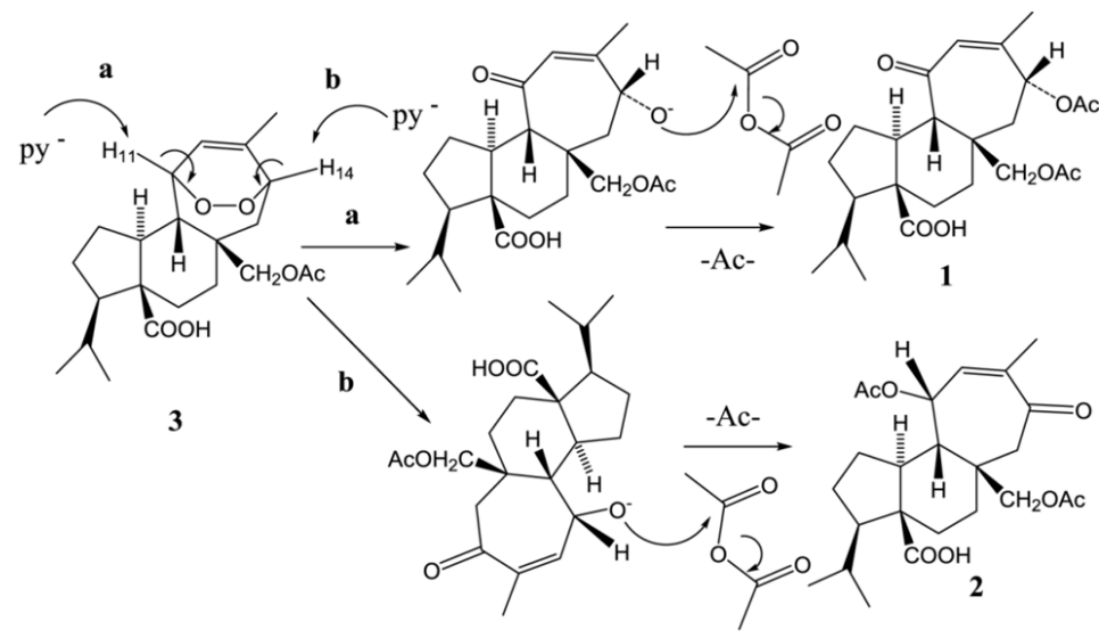

\subsubsection{Computational Analyses and Mechanism of Reaction}

To explain the difference in the reaction yields for compounds $\mathbf{1}$ and $\mathbf{2}$, two possible transition states $\mathrm{TS}_{\mathrm{a}} \mathrm{y} \mathrm{TS}_{\mathrm{b}}$ were designed according to the mechanism proposed (Figure 3 ) to investigate the activation energy for the reactions pathways $\mathbf{a}$ and $\mathbf{b}$.

The geometries of the reactant (compound 3), and transition states $\left(\mathrm{TS}_{\mathrm{a}}\right.$ and $\mathrm{TS}_{\mathrm{b}}$ ) for the two reaction pathways (Figure 3), were optimized using the Gaussian software version 09 software 
package at the $\mathrm{B} 3 \mathrm{LYP} / 3-21 \mathrm{G}^{*}$ level [19]. The structures and imaginary frequencies of transition states were confirmed by the vibration analysis and the intrinsic reaction coordinate (IRC) method at the same level. In pathway a, the activation energy barrier $\mathrm{TS}_{\mathrm{a}}$ is $18.27 \mathrm{~kJ} / \mathrm{mol}$, while in pathway $\mathbf{b}$ the activation energy barrier $\mathrm{TS}_{\mathrm{b}}$ is $20.26 \mathrm{~kJ} / \mathrm{mol}$ (Figure 4). This difference can explain why the base pyridine takes a proton from both $\mathbf{a}$ or $\mathbf{b}$ sides in parallel to produce compounds $\mathbf{1}$ and $\mathbf{2}$. However, the lower energy of $\mathrm{TS}_{\mathrm{a}}$ would reflect a hindered approach of pyridine to the proton $\mathrm{H}_{14}$ in side $\mathbf{b}$ and could explain the higher yield for compound $\mathbf{1}$ (pathway a). Furthermore the higher acidity of leaving proton $\mathrm{H}_{11}$ of side a compared to the acidity of leaving proton $\mathrm{H}_{14}$ in side b (the calculated positive charge of $\mathrm{H}_{11}$ using the Gaussian 09 software is three times higher than $\mathrm{H}_{14}$ ) proved that the reaction step a was favored. This fact was further supported by the calculated transition states for the reaction of mulinane 3 with pyridine. Figure 5 shows the transition states for the subtraction of proton $\mathrm{H}_{-11}$ (TSa) or proton $\mathrm{H}-14\left(\mathrm{TS}_{\mathrm{b}}\right)$ by pyridine and breakage of the endoperoxide as postulated.

Figure 4. Reaction coordinate (reaction steps a, and b) calculated (Gaussian 09) [19] for the reaction between mulinane $\mathbf{3}$ and pyridine leading to compounds $\mathbf{1}$ and $\mathbf{2}$.

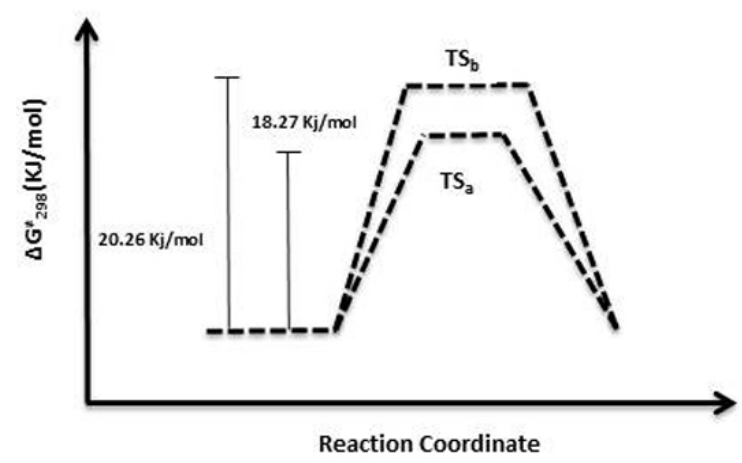

Figure 5. Transition states $\left(\mathrm{TS}_{\mathrm{a}}\right.$ and $\mathrm{TS}_{\mathrm{b}}$, for the reaction steps $\mathbf{a}$, and $\mathbf{b}$ ) calculated (Gaussian 09) [19] for the reaction between mulinane $\mathbf{3}$ and pyridine leading to compounds $\mathbf{1}$ and $\mathbf{2}$.

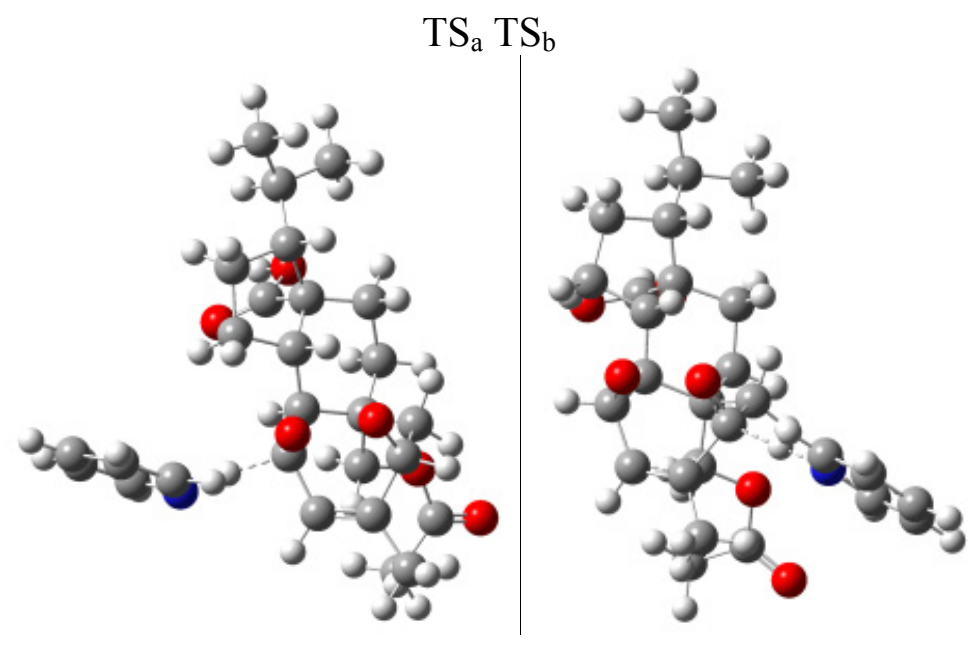




\subsubsection{Semi-Synthesis of Compound $\mathbf{3}$}

The new natural product 5 was also obtained by semi-synthesis from azorellane $\mathbf{6}$ by stirring this compound in $\mathrm{CHCl}_{3}$ at $25{ }^{\circ} \mathrm{C}$ for $48 \mathrm{~h}$, until compound 6 was undetectable by TLC, undergoing the mulinane-azorellane rearrangement reported previously $[10,14,15]$. This reaction proves that the new natural product 5 can be produced from $\mathbf{6}$ in the plant.

\section{Experimental}

\subsection{General Experimental Procedures}

Infrared (IR) spectra were recorded on a 783 FTS 165 FT-IR spectrometer (Perkin Elmer, Waltham, MA, USA). ${ }^{1} \mathrm{H}$ and ${ }^{13} \mathrm{C}$-NMR spectra were recorded on an Avance DRX 500 spectrometer (Bruker Biospin Gmbh, Rheinstetten, Germany) using TMS as internal standard. EIMS and HREIMS spectra were obtained using a MAT 95 XL Mass Spectrometer (Thermo Finnigan, San Jose, CA, USA). Thin-layer chromatography was performed using aluminum-coated silica gel plates (Kieselgel $\mathrm{F}_{254}$, Merck, Darmstadt, Germany) with hexane/EtOAc (9:1) as solvent system. The chromatograms were visualized under UV light $(254 \mathrm{~nm})$ and then sprayed with $1 \%$ vanillin in $\mathrm{EtOH}(w / v)$ and heated $\left(60{ }^{\circ} \mathrm{C}\right)$ to see the compound spots. Medium pressure column chromatography was performed using Kieselgel $60 \mathrm{H}$ (Merck), $55 \mu \mathrm{m}$ particle size, FMI QG 150 medium pressure lab pumps (Syosset, NY, USA) and Ace Glass Inc. medium pressure columns (Vineland, NJ, USA).

\subsection{Plant Material}

Mulinum crassifolium Phil. and Azorella compacta Phil. were collected in El Tatio, Antofagasta, Chile in March 2011. Voucher herbarium specimens are deposited at the Laboratory of Natural Products, University of Antofagasta with the numbers Ac-031511 and Mc-031511, respectively.

\subsection{Extraction and Isolation}

Dried and powdered aerial parts of Mulinum crassifolium $(630 \mathrm{~g})$ were defatted with $n$-hexane (3 times, $1 \mathrm{~L}$ each time, 1 day/extraction) and the remaining plant material was extracted with ethyl acetate (3 times, $1 \mathrm{~L}$ each time, 1 day/extraction) at room temperature for one day each. After filtration, the solvent was evaporated in vacuo yielding a gum $(17 \mathrm{~g})$. The concentrated extract was fractionated on a medium pressure silica gel column $(5 \mathrm{~cm} \times 20 \mathrm{~cm})$ with hexane-ethyl acetate mixtures of increasing polarity as elution solvents to give six fractions (1-6). Fraction 3 (355 mg) was further separated and purified by medium pressure silica gel chromatography $(2 \mathrm{~cm} \times 20 \mathrm{~cm})$ to give $72.2 \mathrm{mg}$ of 17-acetoxymulinic acid (3, Figure S17). Fraction 4 (266 mg) was rechromatographed as above to give compounds $1(95.6 \mathrm{mg})$ and $\mathbf{2}(15.86 \mathrm{mg})$. Fraction $5(327 \mathrm{mg})$ was re-chromatographed as above to give $42.6 \mathrm{mg}$ of mulinolic acid (4) [17]. Dried aerial parts of Azorella compacta (745 g) were defatted with $n$-hexane ( 3 times, $1 \mathrm{~L}$ each time, 1 day/extraction) and the remaining plant material was extracted with ethyl acetate ( 3 times, $1 \mathrm{~L}$ each time, 1 day/extraction) at room temperature for one day each and concentrated as stated above to yield $7.2 \mathrm{~g}$ of a brown gum. The mulinane diterpenoid 5 (25.6 $\mathrm{mg}$ ), together with the known compounds azorellanol (6, $293.4 \mathrm{mg})$ and 13,14-dihydroxy-mulin-11-en-20- 
oic acid $(7,74.2 \mathrm{mg})$ were isolated from this extract by medium pressure column chromatography (Kieselgel $60 \mathrm{H}, 5 \mathrm{~cm} \times 20 \mathrm{~cm}$ ) using the solvent system mentioned above. The structures of the new and known compounds were elucidated by MS and 1D-2D NMR and comparison with literature data $[4,9,17,18]$.

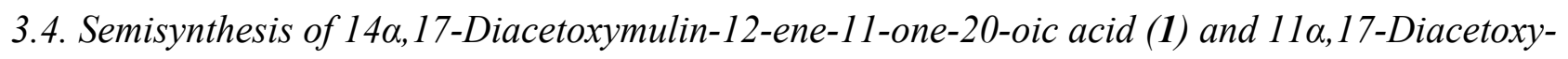
mulin-12-en-14-one-20-oic Acid (2)

A portion $(50 \mathrm{mg}, 0.128 \mathrm{mmol})$ of 3 was dissolved in a mixture of $\mathrm{Ac}_{2} \mathrm{O} / \mathrm{Py}(1: 1,2 \mathrm{~mL})$; the mixture was stirred at room temperature for $24 \mathrm{~h}$ under $\mathrm{N}_{2}$. Afterwards $\mathrm{Et}_{2} \mathrm{O}(10 \mathrm{~mL})$ was added, and the $\mathrm{Et}_{2} \mathrm{O}$ fraction was washed with copper sulphate solution $(4 \times 10 \mathrm{~mL})$ and dried over anh. $\mathrm{Na}_{2} \mathrm{SO}_{4}$. Solvent was evaporated and the remaining reaction products purified by silica gel column chromatography to afford $\mathbf{1}(39.6 \mathrm{mg}, 79.2 \%)$ and $\mathbf{2}(6.5 \mathrm{mg}, 13.0 \%)$.

14a,17-Diacetoxymulin-12-ene-11-one-20-oic acid (mulinone a, 1). White crystals, mp 177-178 ${ }^{\circ} \mathrm{C}$; $[\alpha]_{D}^{25}=+35^{\circ},\left(c=0.200, \mathrm{CHCl}_{3}\right) ;$ IR (liquid film) vmax $\left(\mathrm{cm}^{-1}\right): 3000-3100(\mathrm{br}) ; 1650,1700,1740,1220$; EIMS $m / z$ (rel. int.): $434\left[\mathrm{M}^{+}\right]$(10), $392\left[\mathrm{M}^{+}-\mathrm{COCH}_{3}\right]$ (100), $374\left[\mathrm{M}^{+}-\mathrm{AcOH}\right](7), 314\left[\mathrm{M}^{+}-2 \mathrm{AcOH}\right]$ (45), 286 (44), 243 (35), 91 (34); HREIMS $m / z$ : found 434.2284 (calcd for $\mathrm{C}_{24} \mathrm{H}_{34} \mathrm{O}_{7}, 434.2304$ ); ${ }^{1} \mathrm{H}-\mathrm{NMR} \quad(500.13 \mathrm{MHz})$ and ${ }^{13} \mathrm{C}-\mathrm{NMR} \quad(125.76 \mathrm{MHz})$, data $\left(\mathrm{CDCl}_{3}\right)$ see Table 1 and Supplementary Material.

11 $\alpha, 17-D i a c e t o x y m u l i n-12-e n e-14-o n e-20$-oic acid (mulinone b, 2). White crystals, mp 185-186 ${ }^{\circ} \mathrm{C}$; $[\alpha]_{D}^{25}=-28.11^{\circ},\left(c=0.280, \mathrm{CHCl}_{3}\right)$; IR (liquid film) vmax $\left(\mathrm{cm}^{-1}\right): 3000(\mathrm{br}), 1700,1710,1730,1230$; EIMS m/z (rel. int.): 434 [M ] (10), 392 (100), 350 (10), 331 (5), 286 (44), 169 (17), 105 (18), 91 (25), 55 (38); HREIMS $m / z$ : found 434.2349 (calcd for $\mathrm{C}_{24} \mathrm{H}_{34} \mathrm{O}_{7}, 434.2304$ ); ${ }^{1} \mathrm{H}-\mathrm{NMR}(500.13 \mathrm{MHz}$ ) and ${ }^{13} \mathrm{C}-\mathrm{NMR}(125.76 \mathrm{MHz})$, data $\left(\mathrm{CDCl}_{3}\right)$ see Table 1 and Supplementary Material.

\section{Conclusions}

Based on full spectroscopic evidence, $\mathbf{1}$ and $\mathbf{2}$ are new compounds which were named mulinones a-b. Compounds $\mathbf{1}$ and $\mathbf{2}$ were synthesized thorough acetylation from $\mathbf{3}$ in one step. The mechanism of reaction proposed for the semisynthesis of these diterpenoids was explained by computational analyses. This is the first report of the occurrence of diterpenoid $\mathbf{5}$ in a plant source. These new compounds were semi-synthesized from their precursor natural products-compounds 1-2 from 17-acetoxymulinic acid $\mathbf{3}$ and compound $\mathbf{5}$ from the azorellane diterpenoid $\mathbf{6}$-proving the relationship between them and their parent natural products.

\section{Supplementary Materials}

Supplementary materials can be accessed at: http://www.mdpi.com/1420-3049/19/4/3898/s1.

\section{Acknowledgments}

Financial support by FONDECYT (Grant 1140178), CODEI (University of Antofagasta, Grant 5383) and EULADIV Alfa Project are gratefully acknowledged. 


\section{Conflicts of Interest}

The authors declare no conflict of interest.

\section{References}

1. Munizaga, C.; Gunkel, H. Notas etnobotánicas del pueblo Atacameño de Socaire. Available online: http://www.memoriachilena.cl/archivos2/pdfs/MC0038217.pdf (accessed on 24 March 2014).

2. Chiaramello, A.I.; Ardanaz, C.E.; Garcia, E.E.; Rossomando, P.C. Mulinane-type diterpenoids from mulinum spinosum. Phytochemistry 2003, 63, 883-886.

3. Colloca, C.B.; Pappano, D.B.; Bustos, D.A.; Sosa, V.E.; Baggio, R.F.; Garland, M.T.; Gil, R.R. Azorellane diterpenes from Azorella cryptantha. Phytochemistry 2004, 65, 2085-2089.

4. Loyola, L.A.; Borquez, J.; Morales, G.; Martin, A.S. Diterpenoids from Azorella compacta. Phytochemistry 1997, 44, 649-651.

5. Nicolas, A.N.; Plunkett, G.M. Untangling generic limits in Azorella, Laretia, and Mulinum (Apiaceae: Azorelloideae): Insights from phylogenetics and biogeography. Taxon 2012, 61, 826-840.

6. Neira, I.; Pobleta, L.; Porcille, P.; Silva, P.; Araya, J.; Bórquez, J.; Morales, G.; Loyola, L.A.; Sagua, H. Activity of diterpenoids isolated from Azorella compacta (Llareta) on Trypanosoma cruzi amastigotes. Bol. Chil. Parasitol. 1998, 53, 9-13.

7. Loyola, L.A.; Borquez, J.; Morales, G.; Araya, J.; Gonzalez, J.; Neira, I.; Sagua, H.; San-Martín, A. Diterpenoids from Azorella yareta and their trichomonicidal activities. Phytochemistry 2001, 56, 177-180.

8. Loyola, L.A.; Borquez, J.; Morales, G.; Araya, J.; Gonzalez, J.; Neira, I.; Sagua, H.; San-Martín, A. Azorellane diterpenoids from Laretia acaulis and its toxoplamacidal activity. Bol. Soc. Chil. Quím. 2001, 46, 9-13.

9. Loyola, L.A.; Borquez, J.; Morales, G.; San-Martin, A.; Darias, J.; Flores, N.; Gimenez, A. Muliane-type diterpenoids from Azorella compacta display antiplasmodial activity. Phytochemistry 2004, 65, 1931-1935.

10. Wächter, G.A.; Matooq, G.; Hoffmann, J.J.; Maiese, W.M.; Singh, M.P.; Montenegro, G.; Timmermann, B.N. Antibacterial diterpenoid acids from Azorella madreporica. J. Nat. Prod. 1999, 62, 1319-1321.

11. Morales, P.; Kong, M.; Pizarro, E.; Pasten, C.; Morales, G.; Borquez, J.; Loyola, L.A. Effect of azorellanone, a diterpene from Azorella yareta Hauman on human sperm physiology. J. Androl. 2003, 24, 364-370.

12. Fuentes, N.L.; Sagua, H.; Morales, G.; Borquez, J.; San-Martín, A.; Soto, J.; Loyola, L.A. Experimental antihyperglycemic effect of diterpenoids of llareta Azorella compacta (Umbelliferae) Phil in rats. Phytother. Res. 2005, 19, 713-716.

13. Wächter, G.A.; Franzblau, S.G.; Montenegro, G.; Suarez, E.; Fortunato, R.H.; Saavedra, E.; Timmermann, B.N. A new antitubercular mulinane diterpenoid from Azorella madreporica Clos. J. Nat. Prod. 1998, 61, 965-968. 
14. Delporte, C.; Backhouse, N.; Salinas, P.; San-Martin, A.; Borquez, J. Pharmacotoxicological study of diterpenoids. Bioorg. Med. Chem. 2003, 11, 1187-1190.

15. Bórquez, J.; Loyola, L.A.; Morales, G.; San-Martín, A.; Roldan, R.; Márquez, N.; Muñoz, E. Azorellane diterpenoids from Laretia acaulis inhibit nuclear factor-kappa B activity. Phytother. Res. 2007, 21, 1082-1086.

16. Molina-Salinas, G.M.; Bórquez, J.; Ardiles, A.; Said-Fernández, S.; Loyola, L.A.; San-Martín, A.; González-Collado, I.; Peña-Rodríguez, L.M. Antituberculosis activity of natural and semisynthetic azorellane and mulinane diterpenoids. Fitoterapia 2010, 81, 50-54.

17. Loyola, L.A.; Bórquez, J.; Morales, G.; San-Martín, A. Mulinolic acid, a diterpenoid from Mulinum crassifolium. Phytochemistry 1996, 43, 165-168.

18. Loyola, L.A.; Bórquez, J.; Morales, G.; San-Martín, A. A new diterpenoid from Mulinum crassifolium. Bol. Soc. Chil. Quím. 1997, 42, 311-315.

19. Frisch, M.J.; Trucks, G.W.; Schlegel, H.B.; Scuseria, G.E.; Robb, M.A.; Cheeseman, J.R.; Scalmani, G.; Barone, V.; Mennucci, B.; Petersson, G.A.; et al. Gaussian software, version 09 revision D01; Gaussian Inc.: Wallingford, CT, USA, 2009.

Sample Availability: Samples of the compounds and plant extracts are available from the authors.

(C) 2014 by the authors; licensee MDPI, Basel, Switzerland. This article is an open access article distributed under the terms and conditions of the Creative Commons Attribution license (http://creativecommons.org/licenses/by/3.0/). 